\title{
Repensando a relação entre quadro cênico e cenografia: contribuição para o debate sobre racismo na publicidade $^{1}$
}

\author{
Bruno Deusdará" \\ Décio Rocha** \\ Poliana Coeli Costa Arantes****
}

\section{Resumo}

Considerando a intensificação da expressão da intolerância social na contemporaneidade, propomos, com base em dispositivos do método da cartografia, mapear a produção de imagens discursivas do outro, explicitando a pretensa neutralização ou desqualificação da diversidade. Para tanto, recuperamos a reflexão de Rancière, para quem o ódio à democracia se sustentaria na intolerância à pretensa "inflação" de direitos individuais. Como quadro teórico, partimos de uma concepção polifônica da linguagem e da abordagem do discurso como prática de intervenção sobre o real para interrogar os modos de constituição do sentido para além do plano do dito. Como córpus, recorremos ao texto de uma campanha publicitária de refrigerante cujos pressupostos permitem identificar o silenciamento do debate em torno do racismo, explicitando os embates como remetendo às dimensões geracional, estética e de preferências pessoais. A pesquisa permitiu articular produti- vamente os estudos do discurso e as reflexões contemporâneas acerca do racismo.

Palavras-chave: Gênero. Cenografia. Racismo. Publicidade.

\footnotetext{
Professor de Linguística do Departamento de Estudos da Linguagem, do Instituto de Letras, da Uerj e do Programa de Pós-graduação em Letras, especialidade Linguística. Bolsista dos Programas Prociência (Uerj/ Faperj) e Jovem Cientista do Nosso Estado (Faperj). E-mail: brunodeusdara@gmail.com

** Professor Titular de Linguística e Análise do Discurso do Departamento de Estudos da Linguagem do Instituto de Letras (ILE), Uerj. Professor do Programa de Pós-graduação em Letras do ILE, Uerj, na especialidade Linguística. E-mail: rochadm@uol.com.br

**** Professora do Departamento de Línguas Anglo-germânicas. Ministra as disciplinas Língua alemã, Literatura alemã, Análise do Discurso do Instituto de Letras (ILE), Uerj. Professor do Programa de Pós-graduação em Letras do ILE, Uerj, na especialidade Linguística. Bolsista do Programa Prociência (Uerj/Faperj). E-mail: polianacoeli@yahoo.com.br
}

Data de submissão: ago. 2019 - Data de aceite: out. 2019 http://dx.doi.org/10.5335/rdes.v15i3.9632 


\section{"Mesmo que a gente não seja assim parecido": considerações iniciais}

As práticas científicas nas quais temos investido afirmam a vinculação entre a atividade investigativa e seu entorno socio-histórico como um tipo de relação impossível de ser neutralizada, de ser submetida à pretensão da imparcialidade. Em direção diversa, temos buscado interlocução com pesquisadores que se insurgem contra o primado da representação, caracterizado pela suposição de que o mundo possuiria uma ordem própria e anterior ao conhecimento que dele se poderia obter. Essa interlocução nos interessa por, no mínimo, duas razões.

Primeiro, por permitir atribuir maior atenção ao mundo em constituição, ou seja, por conferir um maior interesse aos movimentos de constituição do real do que aos "estados de coisas" por meio dos quais eles se apresentam. Nisso reside a aposta de que as formas visíveis do mundo não configuram "o" real - supostamente mais autêntico - em relação ao qual novas formas se tornam possíveis. Essas formas visíveis expressam uma parte daquilo que se mantém em elaboração como real. Em outras palavras, temos muito interesse em abordagens que permitam compreender que as mudanças, a instauração do novo não se dá pela substituição de um estado de coisas por outro - o que teria o efeito inconveniente de legitimar o "estado de coisas" atual como "o" real em reação ao qual outras formas se insurgiriam. Assim, a criação não é mera derivação do "dado". Preferimos sustentar que no "estado de coisas" atuam forças diversas, de intensidade e de direção variadas - um paradigma da multiplicidade, tal como formulado por Deleuze e Guattari (1995) -, ainda que apenas algumas de suas dimensões ganhem visibilidade.

Em segundo lugar, por possibilitar conferir às práticas de linguagem um lugar distinto daquele que as apreenderiam sempre com um certo atraso em relação aos eventos. Recusa-se, com isso, a ideia de que primeiro haveria um mundo em constituição e apenas, posteriormente, interviria a linguagem para narrá-lo, versão na qual a linguagem perderia sua força instituinte de novas configurações de mundo, estando presa às cristalizações estabelecidas.

Uma das interlocuções que tem possibilitado contestar o primado da representação do conhecimento sobre o real se estabelece com M. Foucault. Contrapondo teses clássicas a respeito da pré-disposição humana para o conhecer, ele afirma:

O conhecimento, no fundo, não faz parte da natureza humana. É a luta, o combate, o resultado do combate e consequentemente o risco e o acaso que vão dar lugar ao conhecimento. $\mathrm{O}$ conhecimento não é instintivo, é contra-instintivo, assim como ele não é natural, é contra-natural (FOUCAULT, 2002, p. 17). 
Nos termos propostos pelo autor, o conhecimento é mais da ordem da invenção, do que da descoberta:

É contra um mundo sem ordem, sem encadeamento, sem formas, sem beleza, sem sabedoria, sem harmonia, sem lei, que o conhecimento tem de lutar (FOUCAULT, 2002, p. 18).

Assim, o conhecimento emerge como efeito de uma luta, que não encontra no real uma vinculação de continuidade, mas de ruptura, sempre por se fazer. Em evidente convergência com essa perspectiva, Mbembe (2018) desloca a noção de "raça" de qualquer estabilidade pretensamente anterior e a afirma como invenção de dispositivos sociais e técnicos:

Produto de um maquinário social e técnico indissociável do capitalismo, de sua emergência e globalização, esse termo [raça] foi inventado para significar exclusão, embrutecimento e degradação, ou seja, um limite sempre conjurado e abominado (MBEMBE, 2018, p. 21).

Considerando tal ordem de problematizações, uma questão nos move: a que tipo de conhecimento é possível ter acesso por meio de uma prática de análise do discurso? De que modo tem sido possível não restringir esses saberes a uma mera apreensão dos "estados de coisas"? Que dispositivos analíticos têm viabilizado a problematização de um mundo em constituição?

No presente artigo, interessa-nos desenvolver reflexão dirigida a um duplo objetivo. Com efeito, é dupla a nossa proposta: (i) fornecer elementos para um necessário debate a respeito da produção de sentido sobre o negro e sua vinculação com os modos de dizer e fazer ver os racismos, na atualidade; (ii) discutir a produtividade das noções de quadro cênico e cenografia (MAINGUENEAU, 1997, 2001) em uma abordagem teórica que afirma a simultaneidade entre discurso e instituição. Entendemos que esse tipo de proposta assume especial relevância neste momento de profundas alterações no quadro republicano nacional, conforme será possível explorar mais adiante.

Em uma disposição mais tradicional dos projetos de investigação se poderia considerar que o objetivo (i) se dirige mais propriamente à temática a ser investigada e o objetivo (ii) contempla o quadro teórico específico. Nessa disposição, é preciso evitar imaginar que a temática remeta ao mundo exterior e o quadro teórico, às ferramentas adotadas para observar essa exterioridade. Se se pode considerar certo consenso em torno da existência de práticas e políticas racistas fortemente enraizadas nos modos de governar contemporâneos, os diferentes diagnósticos que conduzem a esse consenso demonstrarão uma forma diversa, heterogênea e, em alguns casos, conflitante de abordar a questão tida inicialmente como consensual. Como se vê, a crítica ao primado da representação oferecerá resistência a esse binarismo exterior/interior, por meio do qual se 
sugere a cristalização das formas atuais dessa exterioridade.

$\mathrm{Na}$ interseção entre temática e quadro teórico, movemo-nos numa inspiração arqueológica, para a qual uma investigação das práticas discursivas possibilita problematizar a formação dos objetos e dos sujeitos. Para Foucault, a prática discursiva se define por

[...] um conjunto de regras anônimas, históricas, sempre determinadas no tempo e no espaço, que definiram, em uma dada época e para uma determinada área social, econômica, geográfica ou linguística, as condições de exercício da função enunciativa (FOUCAULT, 2004, p. 133).

A partir dessas diretrizes e inspirações, propomos, para este artigo, um itinerário que se inicia por uma tomada de posição frente à emergência e à intensificação das intolerâncias (RACIÈRE, 2014) na atualidade e sua articulação com os debates acerca do racismo (MBEMBE, 2018).

$\mathrm{Na}$ sequência, enfatizamos, na explicitação das ferramentas teóricas que caracterizam a perspectiva discursiva na qual temos investido, o debate a respeito da configuração das cenas do discurso. Na formulação proposta por D. Maingueneau (1997, 2001), o quadro cênico - que reúne a cena englobante, proveniente do tipo de discurso, e a cena genérica, instituída pelo gênero do discurso - inscreve as práticas de linguagem em um cenário estável, que seria recoberto por uma "cilada" produzida pela cenografia.
Consideramos, desse modo, que o tipo de material escolhido para as análises empreendidas permite justamente colocar em questão o encadeamento das cenas originalmente sugerido pelo autor.

Por fim, quando elegemos um anúncio publicitário como materialidade intersemiótica a ser analisada, não pretendemos que seja uma "amostra representativa" de um conjunto de discursos, mas uma textualidade cuja emergência forneça indícios de um regime de materialidade enunciativa, que é

[...] mais da ordem da instituição do que da localização espaço-temporal; define antes possibilidades de reinscrição e de transcrição (mas também limiares e limites) do que individualidades limitadas e perecíveis (FOUCAULT, 2004, p. 116).

\section{"Nós não temos o cabelo tão cacheadinho e lindo como o seu": sobre racismo e intolerância}

Consideramos a recente reviravolta nas referências e nos valores que orientam o debate público na cena republicana nacional como motivação inescapável para a análise a ser desenvolvida no presente artigo. Trata-se, a nosso ver, de tarefa urgente a busca por compreender os jogos de força, os embates e as lutas sociais que tenham concorrido para o aparecimento e a rápida acomodação de modos de dizer e de agir movidos por um ímpeto de combate 
e destruição das chamadas minorias nas formas de governo e nos espaços instituídos da administração pública.

Dessa maneira, por "reviravolta" pretendemos designar o modo como o desejo de interrupção abrupta do processo de reconhecimento das diversidades de modos de apreender, sentir e viver, e de ampliação de direitos sociais e individuais, na história recente do país, assumiu feições visíveis e cristalizadas. Caracterizamos como abrupta sua forma de emergência, indicando o curto lapso temporal em que manifestações de rua se convertem em vitórias em pleitos eleitorais, considerados os últimos quatro anos.

$\mathrm{Na}$ variedade dos embates, conferimos especial atenção à maneira como esse desejo de destruição de conquistas recentes e em vias de consolidação investe em formas racistas, machistas, homofóbicas, ao lado das capturas policialescas - vontades expressas de restituição de governos autoritários, por exemplo.

A exemplo das reivindicações pela ampliação dos direitos sociais de grupos minoritários diversos, percebe-se que, ao lado das lutas por conquistas de direitos básicos a grupos historicamente alijados de reconhecimento e do exercício de direitos fundamentais, emergem contestações que parecem atribuir aos estados democráticos a suposta abertura de condições para uma pretensa "inflação" dos direitos individuais, instaurando a emergência de um novo ódio social, segundo o qual seria "necessário lutar contra a democracia, porque a democracia é o totalitarismo" (RANCIÈRE, 2014, p. 117).

Ressalte-se, nesse sentido, a observação de Rancière segundo a qual o ódio à democracia vem sendo reforçado por uma "confusão" no plano da linguagem. Os avanços necessários na conquista de uma ampliação de direitos individuais a grupos minoritários anteriormente alijados de reconhecimento social vêm sendo apontados como elementos de restrição, de limitação dos privilégios de grupos estabelecidos. Esse modo de conceber o exercício democrático o julgaria limitador da própria democracia quando, segundo esse modo de pensar, ela "se deixa corromper pela sociedade democrática que quer que todos sejam iguais e que todas as diferenças sejam respeitadas" (RANCIÈRE, 2014, p. 10).

Nesse contexto, a investigação dos processos de subjetivação em curso não pode incorrer no equívoco de supor que pudesse proceder à mera descrição das representações da necessária ampliação das margens do exercício democrático e das limitações opostas pelo emprego desmedido do aparato policial e por iniciativas individuais de ataques que pretendem habitar o território comum motivados pelo projeto de restrição absoluta da alteridade ou mesmo sua destruição. A esse respeito, é preciso considerar a insuficiência do plano dos conteúdos (ROCHA; DEUSDARÁ, 2005, 2006). 
Essas duas premissas que orientam a prática de análise - a dos limites da ordem do dito e a da tentativa de restituir os modos de dizer - possibilitam acessar a dimensão paradoxal dos modos de vida. É também por meio de um paradoxo que Mbembe define a condição do negro nas sociedades ocidentais: por um lado, "Humilhado e profundamente desonrado, o negro é, na ordem da modernidade, o único de todos os humanos cuja carne foi transformada em coisa e o espírito em mercadoria", por outro lado, "tornou-se o símbolo de um desejo consciente de vida, força pujante, flutuante e plástica, plenamente engajada no ato de criação e até mesmo de viver em vários tempos e várias histórias simultaneamente" (MBEMBE, 2018, p. 21).

$\mathrm{Na}$ denúncia relativa aos atos de intolerância racial a que procede, Mbembe explicita a dimensão filosófica que sustenta sua reflexão. Dela, destacamos a indissociabilidade entre o "material" e o "fantasmático", o que lhe permite destacar a simultaneidade das "devastações psíquicas assombrosas" com os "incalculáveis crimes e massacres". Com efeito, o autor contribui para a superação da dicotomia enraizada entre um pretenso substrato empírico-biológico e a construção sócio-psíquica do racismo. Trata-se, em ambos os planos, de um funcionamento complexo articulado. Para o autor, a raça não é apenas o que se efetua por meio de processos econômicos, políticos, sociais, psíquicos, é igualmente matéria-prima de relações coloniais, bélicas, comunitárias:

Enfim, a raça é uma das matérias-primas com as quais se fabrica a diferença e $o$ excedente, isto é, uma espécie de vida que pode ser desperdiçada ou dispensada sem reservas. Pouco importa que ela não exista enquanto tal, e não só devido à extraordinária homogeneidade genética dos seres humanos. Ela continua a produzir efeitos de mutilação, porque originariamente é e será sempre aquilo em cujo nome se operam cesuras no seio da sociedade, se estabelecem relações de tipo bélico, se regulam as relações coloniais, se distribuem e se aprisionam pessoas cuja vida e presença são consideradas sintomas de uma condição-limite e cujo pertencimento é contestado porque elas provêm, nas classificações vigentes, do excedente (MBEMBE, 2018, p. 73).

No debate proposto pelo autor, observa-se um interessante paradoxo: embora não exista enquanto tal, a "raça" não deixa de servir de matéria-prima de uma fabricação constante, cujos efeitos deixam marcas no funcionamento das relações sociais, na dinâmica de distribuição dos corpos nos espaços, nos modos de vida psíquica. $\mathrm{O}$ que esse funcionamento faz ver é não a apropriação imaginária de algo que teria realidade pretensamente exterior. Ao contrário, esse funcionamento se inscreve em seus processos de constante fabricação daquilo que pretende configurar como real - a evidência das marcas de distinção racial. Tais reflexões oferecem elementos bastante produtivos na configuração do debate em torno da exposição (articulado a um silenciamen- 
to?) da distinção racial que, conforme veremos, observamos se inscrever em uma dada campanha publicitária.

\section{"Eu sei o que vocês estão querendo dizer": sobre a tríplice cena}

Neste item, concentramos nossa discussão nas ferramentas teóricas que caracterizam o tipo de Análise do Discurso em que temos investido. Preliminarmente, cabe recuperar o modo como Maingueneau (1997) delimita a noção de prática discursiva - reversibilidade textual e social dos discursos. Essa definição possui o mérito de considerar o discurso como um funcionamento em constante (re)articulação, a que o autor designou por enlaçamentos paradoxais (MAINGUENEAU, 1997). Com o intuito de sustentar a complexidade do debate tal como proposto por Mbembe, elegemos a articulação quadro cênico/cenografia como ferramentas conceituais pertinentes à análise proposta. Esses dispositivos analíticos emergem na obra de Maingueneau no contexto de sua reflexão sobre os discursos literários, mantendo-se produtivos em seus trabalhos mais recentes. Entre as diversas motivações que nos conduzem ao referencial teórico apresentado, a articulação entre quadro cênico e cenografia interessa-nos especialmente pelo que sugere a respeito da relação entre discurso e instituição.
Para Maingueneau, a cena englobante caracteriza o tipo de discurso, ao passo que a cena genérica remete às determinações do gênero do discurso. Para o autor, a articulação entre as referidas cenas compõe o ‘quadro cênico', como um “espaço estável no interior do qual o enunciado adquire sentido" (MAINGUENEAU, 2001, p. 87). A esse "espaço estável" viria somar-se a cenografia, configurando-se como cena que institui uma espécie de "cilada", um primeiro plano que buscaria legitimar a própria enunciação.

Num certo sentido, o quadro cênico inscreve o espaço estável a partir do qual se torna possível enunciar, em função do qual a cenografia designaria um arranjo novo, um certo movimento desse quadro estável. Não é difícil compreender de que modo a correlação estabelecida anteriormente inscreve os termos na problemática que vincula o dado e o atual, o estável e o movente, ou, para retomar uma tensão em termos próprios ao pós-estruturalismo, a repetição e a diferença.

Fornecendo bases conceituais que procuram evitar a extremada cristalização desse espaço estável a partir do qual é possível enunciar, Rocha (2013) propôs uma revisão da articulação gênero do discurso/cenografia, que pretendia assumir o primeiro termo como forma sempre presente e o segundo como acontecimento eventual (acidental?). Em outras palavras, em sua compreensão de como deveriam se articular quadro cênico e 
cenografia, Rocha (2013) buscava evitar que as coerções genéricas fossem vistas como essenciais e anteriores à escolha de uma cenografia e que, por esse motivo, os gêneros se dividissem em duas categorias: os que permitiriam e os que não permitiriam um investimento diversificado no que diz respeito à cenografia.

De que forma Maingueneau articula as noções de quadro cênico e cenografia? Segundo o autor, a cenografia viria de algum modo recobrir o quadro cênico: no caso do anúncio publicitário que elegemos como córpus para o presente trabalho, o interlocutor - espectador de um anúncio de TV - se veria às voltas com uma cena de interação em família, uma conversa entre pais e filha, acerca de um tema delicado - a adoção - que, ao que tudo indica, estaria sendo abordado pela primeira vez, já que os pais têm dificuldade de dizer clara e diretamente que a filha é adotiva. A captura do espectador por essa primeira cena vem explicitar que esse espectador é interpelado em uma identidade muito específica: a de quem aprecia cenas de convívio familiar e com elas se identifica ou delas deseja tirar alguma lição que lhe seja útil, o que indica ser aquela cena particularmente importante também para ele. Somente num momento posterior o interlocutor se daria conta de que se trata de uma publicidade, instante no qual descobriria a cilada ${ }^{2}$ em que foi pego pelo recurso a uma cenografia.
Propomos aqui uma outra leitura da função exercida pela cenografia que nos ajudará a reconfigurar sua relação com a noção de quadro cênico. Diremos que, desde os primeiros instantes em que faz contato com a cena da família à mesa, o espectador percebe tratar-se de uma publicidade veiculada sob o formato de propaganda televisiva. Há, com efeito, inúmeras pistas que denunciam a presença de uma publicidade para um espectador que possua alguma familiaridade com as emissões televisivas. Logo, ele já está plenamente consciente do tipo de discurso e do gênero: a cena englobante é a do discurso publicitário, e a cena genérica, a publicidade transmitida na tela. Consequentemente, esse espectador sabe que a cenografia de conversa em família na hora da refeição é um meio possível para chegar à publicidade. Porém, tendo em vista que tal cenografia é identificada enquanto tal com base no reconhecimento prévio das cenas englobante e genérica, não mais poderemos dizer tratar-se de uma cilada: o espectador não se deixa aprisionar por nenhuma armadilha que lhe capture a atenção e que, em seguida, viria a se revelar em sua identidade de publicidade. Diremos, então, que, ao invés de cilada, mais valerá apostar na função "confabulação", a qual definiremos como "ato ou efeito de contar histórias fantasiosas como verdade", que é uma das definições para o termo no dicionário Houaiss. Assim, enunciador e coenun- 
ciador experimentam a ideia de (re)viver indefinidas vezes uma mesma narrativa que sabem ser fantasiosa - a da família que vive harmoniosamente seu cotidiano por compartilhar um certo produto. Eis, assim, mais uma razão para renomearmos a "cilada" como "confabulação": se a ideia de cilada já não era conveniente para caracterizar uma situação que se revelava imediatamente como uma publicidade, ou seja, que se tratava desde sempre de uma ficção, menos ainda o será se for considerado que o gozo de tal ficção se dá tantas vezes quantas forem a exibição da publicidade. Dito em outras palavras, numa cilada se cai por distração, por se estar desprevenido, sendo pouco plausível que uma mesma emboscada funcione um número indefinido de vezes, mas pode-se fruir o feliz encontro de uma cena validada, ou cenário validado, isto é, uma cena já instalada no universo de saber e de valores do público (MAINGUENEAU, 1995 p. 126), que seja positivamente valorizada um sem número de vezes. A esse respeito, acrescentemos que não será difícil encontrar cenas muito semelhantes de conversa em família ao redor da mesa em que o produto propagandeado é uma determinada marca de margarina, de embutidos e outros mais.

Uma vez que a publicidade é reconhecida como tal desde o momento inicial de sua exibição na tela, restará ao espectador tão somente uma dupla tarefa: (i) descobrir qual o produto anunciado (no caso da publicidade que escolhemos, a garrafa de Coca-Cola já está sobre a mesa, mas será preciso algum tempo para ser identificada, uma vez que, no início, é muito rápida a exposição do slogan "abra a felicidade", o qual será entendido como um convite a que se beba Coca-Cola); (ii) estabelecer uma relação entre a cenografia criada e o produto-alvo da propaganda. Relação que o slogan final deixa bastante clara: "Comer juntos alimenta a felicidade. Abra a felicidade".

\section{"[...] o que importa são as coisas iguais que a gente sente": análise}

A peça publicitária escolhida como córpus deste trabalho fez parte de uma campanha de 2015 da empresa Coca-Cola, cujo slogan, "Comer juntos alimenta a felicidade", foi veiculado em vídeos em canais abertos de televisão e em inserções em telenovelas, sendo posteriormente disponibilizados em um hotsite ${ }^{3}$.

A campanha apoiou-se fortemente na temática das refeições em família para se alimentar junto ao público e, assim, procurou diversificar a apresentação de diferentes constituições familiares, indicando que as produções seriam um modo de combater preconceitos. No entanto, a análise dos pressupostos e subentendidos dos enunciados de uma dessas publicidades em particular nos pareceu sub-repticiamente reforçar o ra- 
cismo. Por essa razão, centramos nossas reflexões no referido texto.

As coordenadas de espaço e tempo do texto publicitário em questão são construídas a partir da recuperação de uma cena validada, ou cenário de enunciação validado (MAINGUENEAU, 1995, p. 126), que, no caso em análise, coincide com a "refeição em família", um cenário validado certamente valorizado. Os índices dessa inscrição são enunciados prioritariamente por meio de elementos visuais que compõem o enquadramento cênico, tal como se poderá explicitar a seguir.

A esse respeito, cabe observar que as pistas que indicam tratar-se de uma refeição em família foram construídas apenas por índices não verbais, a saber: i) os três personagens encontram-se sentados à mesa; ii) sobre a mesa, há pratos com alimentos aparentemente apenas servidos; iii) sobre a mesa, há a garrafa do refrigerante (em oferta pela peça) e copos ainda cheios, sugerindo não terem sido bebidos; iv) atrás dos personagens pais, há uma bancada que aparenta ser de pedra típica de ambientes de cozinha, com pratos e xícaras dispostos em um secador de louça sobre a pia, ao lado da cuba; v) sobre a bancada da cozinha, há também frutas e um liquidificador. Desse modo, o espaço construído remete a uma refeição familiar que se realiza na cozinha da casa, ao passo que o tempo se constrói relativamente à própria realiza- ção da refeição, com marcas bastantes fortes de que se trataria de seu início.

Apresentamos a seguir o enquadramento inicial do vídeo, que permite a observação dos elementos descritos anteriormente:

Figura 1 - Enquadramento inicial "argumentos apresentados por mãe e pai”

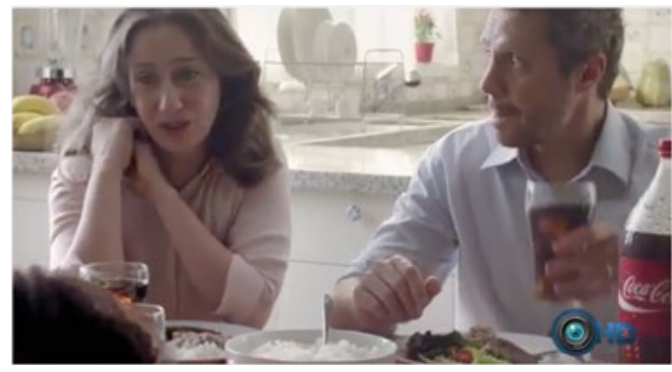

Nesse enquadramento, transcorre a parte inicial do diálogo, cuja transcrição encontra-se a seguir:

- Meu amor, eu e o papai... nós não temos o cabelo tão cacheadinho e lindo como o seu...

- É, e, mesmo que a gente não seja assim parecido, [por]que você é muito mais bonita e muito mais inteligente que nós dois...

- Nós somos os seus pais.

Figura 2 - Enquadramento final "réplica da filha"

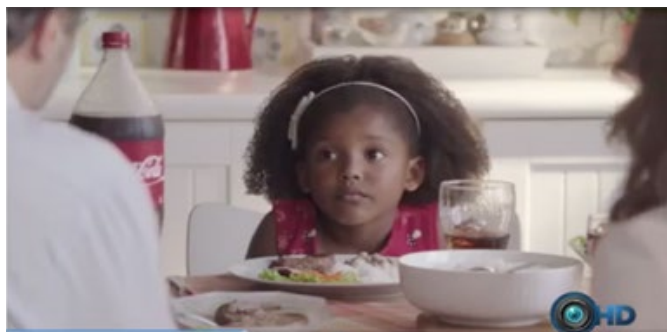


No enquadramento seguinte, segue a fala da personagem criança:

- Eu sei o que vocês estão querendo dizer. Mesmo que vocês gostem de beterraba e eu não, o que importa são as coisas iguais que a gente sente e é por isso que eu adotei vocês, tá bom?

Ao final da publicidade, é apresentado, em destaque, o seguinte slogan: "Comer juntos alimenta a felicidade". "Abra a felicidade" (ao lado de duas garrafas de Coca-Cola).

Considerando o aparente distanciamento entre o que se apresenta no plano verbal e no plano não verbal, distanciamento que se intensifica quando se constata que o não verbal é responsável pela problematização flagrante de uma família cuja composição racial heterogênea (pais brancos e filha negra) é muito timidamente abordada pelo texto construído pelos pais, optamos por investir na busca de implícitos (pressupostos e subentendidos) desse plano verbal. Em perspectiva discursiva, o fenômeno do pressuposto marca a seguinte relação entre um enunciado efetivamente dito e um espaço do dizível: "um dizer reassume um dizível não necessariamente formulado/formulável, recuperando uma memória discursiva associada à formação discursiva, através da repetição, da recusa ou da reformulação (reformulação do que não foi formulado em alguns casos)” (SILVA, 2015, p. 104-105).
Segue a explicitação de pressupostos $\left(\mathrm{P}^{1}\right.$ a $\left.\mathrm{P}^{18}\right)$ e subentendidos $\left(\mathrm{S}^{1}\right.$ a $\left.\mathrm{S}^{8}\right)$ que se depreendem em cada enunciado (E1 a E6):

E1: "meu amor, eu e o papai, nós não temos o cabelo tão cacheadinho e lindo como o seu"

$\mathrm{P}^{1}$ cabelo cacheado é lindo

$\mathrm{P}^{2}$ você [a menina] possui cabelo cacheado e lindo

$\mathrm{P}^{3}$ aqui em casa prestamos atenção ao cabelo e fazemos comparações $\mathrm{P}^{4}$ seria de se esperar que nós também tivéssemos cabelos (tão) cacheados $\mathrm{S}^{1}$ a mãe sente necessidade de reafirmar um sentimento de amor pela filha

$\mathrm{S}^{2}$ ao se referir ao marido como "papai”, a mãe assume a perspectiva da filha, reafirmando o lugar de fala da criança na família

E2: "é, e mesmo que a gente não seja assim parecido, [por]que você é muito mais bonita e muito mais inteligente que nós dois"

$\mathrm{P}^{5}$ não ser parecido pode ser índice de algum tipo de problema

$\mathrm{P}^{6}$ pais e filhos costumam ser parecidos

$\mathrm{P}^{7}$ filhos costumam ser tão bonitos quanto os pais

$\mathrm{P}^{8}$ filhos costumam ser tão inteligentes quanto os pais 
Em E2, o pressuposto $\mathrm{P}^{6}$ só pode ser extraído a partir de uma leitura global do texto, pois a referência ao fato de os adultos serem os pais (adotivos) da menina somente é apresentada ao final e, ainda assim, de um modo indireto, na fala da própria menina ("é por isso que eu adotei vocês, tá bom?”).

E3: "Nós somos os seus pais"

$\mathrm{P}^{9}$ a menina tem pais

$\mathrm{S}^{3}$ ao reafirmar que eles são seus pais e que, portanto, a criança tem uma família, a mãe parece tentar afastar uma ideia sempre recorrente nos casos de adoção, a saber, a ideia de criança abandonada.

E4: "Eu sei o que vocês estão querendo dizer"

$\mathrm{P}^{10}$ os pais querem dizer algo

$\mathrm{P}^{11}$ os pais não estão sendo claros no que querem dizer

$\mathrm{P}^{12}$ falamos para dizer algo

E5: "Mesmo que vocês gostem de beterraba e eu não, o que importa são as coisas iguais que a gente sente"

$\mathrm{P}^{13}$ gostar de beterraba é uma característica importante

$\mathrm{P}^{14}$ gostar das mesmas coisas pode aproximar as pessoas

$\mathrm{P}^{15}$ Não gostar das mesmas coisas não necessariamente afasta as pessoas
$\mathrm{P}^{16}$ não gostar de beterraba não é característica suficiente para não gostar de alguém

$\mathrm{P}^{17}$ sentir coisas iguais é motivo para adoção de pessoas (pais)

$\mathrm{S}^{4}$ ser adotado pode ser um problema para a criança

$\mathrm{S}^{5}$ pais e filhos deveriam ser parecidos

$\mathrm{S}^{6}$ se filhos e pais possuem hábitos distintos, pode ser que não se gostem.

$\mathrm{S}^{7}$ para adotar alguém, é preciso reconhecer semelhanças

E6: "e é por isso que eu adotei vocês, tá bom?"

$\mathrm{P}^{18}$ há sempre uma razão que justifica $o$ ato de adoção

$\mathrm{S}^{8}$ se os pais têm dificuldade de verbalizar que adotaram a menina, ela, a seu turno, não demonstra ter qualquer dificuldade a respeito

Muitos dos elementos implícitos que contribuem para a compreensão do diálogo ganham visibilidade por intermédio das estruturas concessivas presentes no texto ("mesmo que a gente não seja assim parecido", "mesmo que vocês gostem de beterraba e eu não"), que são responsáveis por deixarem transparecer uma certa "falta": não ser assim tão parecido ou não ter a mesma opinião a respeito 
de beterraba podem, afinal, constituir índices de distanciamento ou de falta de afinidade entre as pessoas. Com efeito, o diálogo deixa pressentir a presença de elementos adversos a um verdadeiro encontro familiar, os quais são imediatamente afastados por meio das construções concessivas: "não somos parecidos e não gostamos das mesmas coisas, mas, ainda assim, esforçamo-nos por nos mantermos próximos e em harmonia."

Observamos, por meio dos levantamentos acima descritos, que o diálogo constrói e reforça imagens e modos de conceber a família em torno do que seriam identificações por semelhança. No entanto, com a identificação de muitos traços distintos entre os membros da família apresentados, sobretudo de caráter estético (cabelo cacheado, beleza aparente), percebem-se embates que colocam os pais em contraste com a filha, tomando os pais como referência. Nesse sentido, percebe-se uma tensão de ordem racista, pois a perspectiva da diferença entre pais e filhos foi focalizada no contexto estético, que os torna, por esse motivo, diferentes.

Mais pistas sobre a tensão racista que se estabelece no diálogo estão localizadas, por exemplo, no eufemismo utilizado para caracterizar os cabelos da menina: "cacheadinho" ao invés de "crespo". De modo semelhante, o reforço do adjetivo "lindo" para caracterizar o cabelo da menina também nos indica a "necessidade" de se afirmar que o cabelo da menina é lindo, perante algumas vozes que poderiam dizer o contrário. Pode-se mesmo subentender que o cabelo da menina é lindo justamente por ser cacheado. Ao reforçar essa tese, ao dizer que os pais não têm cabelos lindos como o da filha, instaura-se no discurso o seguinte questionamento subentendido: há quem considere que o cabelo da menina não é bonito? Qual a necessidade de se afirmar que os pais não têm cabelos lindos, em comparação ao cabelo da menina? Ao comparar o cabelo da menina com o dos pais, a mãe afirma que os cabelos dela e os do pai não são lindos como os da filha. Nesse sentido, instaura-se um enunciado polêmico em debate: cabelos cacheados não seriam lindos?

\section{Considerações finais: "tá bom?"}

A publicidade coloca em cena uma diversidade de embates que se constroem em diferentes planos, comprometendo em diferentes níveis as cenas em que se organiza a enunciação. Com efeito, são diversos os embates a que se assiste: (i) um embate geracional envolvendo adultos (os pais) e a criança (a filha); (ii) um embate estético, onde cabelos cacheados e lindos se opõem a um elemento de alteridade qualquer, não nomeado na publicidade, mas apenas descrito como "não tão cacheadinho e lindo"; (iii) um embate alimentar, que coloca em cena os que gostam e os que não gostam de beterraba; (iv) um 
embate no modo de composição familiar, opondo-se o biológico ao socioafetivo; (v) finalmente, um embate no plano verbal, onde à enunciação vacilante e cautelosa dos pais se contrapõe a enunciação eloquente e segura da criança. É este último nível de embate, que tem lugar no plano verbal, que ora queremos aprofundar, tendo em vista a possibilidade de se pensar um novo modo de articulação entre quadro cênico e cenografia.

Conforme vimos, de acordo com o autor, teríamos um quadro cênico que se desdobra em cena englobante (discurso publicitário) e cena genérica (anúncio televisionado). Para o autor, tais cenas compõem a dimensão estável a ser desestabilizada por uma cenografia que serviria, em princípio, como cilada. Assim, a "conversa em família" a que se assiste se instituiria recobrindo o quadro cênico e simulando tratar-se de outra textualidade que não a de um anúncio. Engodo cuja verossimilhança é muito frágil, tendo em vista que, além de ser apresentado justamente no intervalo de uma programação televisiva, no período de tempo destinado precisamente aos anúncios televisivos - situação que faz parte dos saberes de qualquer telespectador -, o vídeo em questão é introduzido por uma cena em que se exibe uma garrafa de Coca-Cola.

Desse modo, além do fato de ser pouco plausível que tal cenografia funcione efetivamente como uma cilada em função dos argumentos apresentados, outro elemento parece bastante eloquente acerca do modo como se articulam as cenas no referido material. A diversidade étnica encontra-se fortemente marcada no plano não verbal, com a apresentação de um casal branco e uma menina negra. Já no plano verbal, tal diversidade encontra-se reduzida a uma tematização das aparências físicas ("e, mesmo que a gente não seja assim parecido"), rapidamente desdobrada em outros termos ("[por]que você é muito mais bonita e muito mais inteligente que nós dois..."). A contradição que se marca entre o plano verbal, onde a diversidade étnica apresenta-se tão marcadamente na distribuição das personagens, e a simplificação com que a questão racial é explorada verbalmente na publicidade parece atender ao "anseio por um mundo sem surpresas, sem cortinas, sem formas complexas", "a expressão da resistência à multiplicidade”, conforme destaca Mbembe (2018, p. 200).

Em sustentação à ideia de que o plano verbal vem mitigar o embate que se encena, lembramos que os elementos de análise presentes no item anterior corroboram a hipótese de uma tensão silenciada na breve interlocução entre pais e filha. Com efeito, se o texto se apresenta algo lacunar, deixando em suspenso algumas das apreensões dos pais no momento de enunciar, muito é "dito" por meio dos pressupostos e também das construções concessivas. 
Tendo em vista o referido silenciamento, em tal configuração, a convocação da diversidade étnica parece remeter mais ao plano do tipo de discurso atribuindo-se responsabilidade por sua emergência ao enunciador-publicitário - do que à cenografia, tendo em vista que a conversa amigável em família não parece ter "fôlego" para um debate que enfrente as dificuldades implicadas nas questões raciais. Em outras palavras, na "conversa em família", nada acontece que se possa destacar como relevante para a tematização do que se enuncia por meio das opções imagéticas explicitadas ${ }^{4}$. Desse modo, o enunciador-publicitário, que enuncia também por intermédio dos elementos pictóricos que põe em cena, não se permite ocultar por detrás da simulação de uma conversa em família. Ele se torna presente, entre outros aspectos, por exibir um conflito racial que se supõe passível de ser neutralizado pelo investimento cenográfico.

Rocha (2013) já havia proposto evitar que se assumisse uma certa precedência dos gêneros do discurso frente às cenografias, contrariamente à perspectiva que havia levado Maingueneau, em determinado momento, a postular a existência de gêneros sem cenografia. Para Rocha, as cenografias evidenciariam um certo movimento que se cristalizaria na configuração - sempre movente - dos gêneros. Neste artigo, pretendemos avançar em um outro aspecto: a ideia de que essa pretensa precedência dos gêneros sobre as cenografias as tenha fixado num funcionamento em cilada. Com efeito, a ideia de uma conversa em família vindo se sobrepor a um gênero anteriormente definido - uma publicidade na televisão - só pode fazer sentido como elemento distrator que, por distrair, acaba funcionando como cilada. Como assegurar, no entanto, que se trata de uma publicidade televisiva sem o apoio de uma imagem e de um texto que, no caso em tela ${ }^{5}$, remetem justamente a uma conversa em família? Não seria antes o caso de dizer que, diante do projeto de publicidade de uma bebida junto a uma certa fração de público, isto é, diante do encontro de forças que têm origem em um projeto de dizer e um interlocutor, a forma que acaba ganhando consistência é a da conversa em família. Em outras palavras, não existe um dado previamente instituído - a publicidade de um refrigerante - que acabaria se transmutando em conversa em família. Ao contrário, a conversa em família é o plano possível de interlocução entre anunciante e consumidor, tendo em vista se tratar, como vimos anteriormente, de uma cena validada e positivamente valorizada por esse consumidor. Trata-se, como indicamos anteriormente, da "confabulação" possível entre uma dada qualidade de interlocutores. Assim, parece-nos legítimo supor que, fosse outro o consumidor previsto como interlocutor, situado em um outro espeço e em um ou- 
tro momento, outra seria a forma encontrada para dar materialidade ao projeto de dizer. Entendemos que, por essa via, não naturalizamos um dado "estado de coisas" como sendo o real, o qual seria substituído por um novo estado que "subverteria a ordem instituída". Como dissemos anteriormente, o novo não resulta da sucessão de diferentes estados que vão se superpondo, e sim do encontro de forças diversas que viabilizam diferentes conformações, dentre as quais algumas ganham visibilidade e outras não. Se chamarmos de "aparência" as formas que, surgidas em dado momento, respondem pelo encontro fortuito de forças em disputa, então reencontraremos a perspectiva de Mbembe para falar de "realidade":

A força da raça deriva precisamente do fato de que, na consciência racista, a aparência é a verdadeira realidade das coisas. Em outras palavras, a aparência, neste caso, não é o contrário da "realidade" (MBEMBE, 2018, p. 200).

\section{Rethinking the relationship between scenic framework and scenography: a contribution to the debate on racism in advertising}

\section{Abstract}

Considering the growing of social intolerance in contemporaneity, we propose, based on devices of cartography method, to map the production of discursive images of the other, explaining the pretense neutralization or disqualification of diversity. To this end, we relied on Rancière, according to whom the hatred of democracy would sustain itself in intolerance to the alleged "inflation" of individual rights. Our theoretical framework includes a polyphonic conception of language and discourse as a practice of intervention on the real to interrogate the ways of constitution of meaning beyond the plan of what is said. As a corpus, we make use of the text of an advertising campaign whose assumptions allow us to identify the silencing of the debate over racism, explaining the conflicts as referring to generational, aesthetic and personal reasons. The research allowed to articulate productively discourse studies and contemporary reflections about racism.

Keywords: Genre. Scenography. Racism. Advertising.

\section{Notas}

1 A disposição dos nomes dos autores segue estritamente a ordem alfabética.

2 A referência ao termo cilada (ou a um reformulante seu) está ausente na última obra de Maingueneau, Discurso e Análise do discurso, de 2015. Considerando, porém, que o autor não desabona o uso do termo, reiteradamente utilizado em trabalhos anteriores seus (como é o caso da presença de cilada e armadilha respectivamente em MAINGUENEAU, 2002, p. 87 , e 2006 , p. 121), julgamos procedente e relevante o presente debate.

3 Página na web voltada a uma ação publicitária de uma empresa específica, geralmente com tempo de veiculação limitado à ação publicitária. Hotsite "Comer Juntos". Plataforma Gshow da Rede Globo de Televisão. Disponível em: http://gshow.globo.com/comer-juntos/. Acesso em: 15 maio 2017. 
4 Como se percebe, em consonância com Maingueneau (2005, p. 147) consideramos que imagens também constituem textos sujeitos às mesmas coerções e possibilidades do plano enunciativo.

5 Empregamos a expressão em um duplo sentido: (i) no caso do qual estamos tratando no momento; (ii) no caso ao qual assistimos projetado na tela da televisão.

\section{Referências}

BAKHTIN, M. Marxismo e Filosofia da Linguagem. São Paulo: Hucitec, 2004.

DELEUZE, G. Conversações. Trad. de Peter Pál Pelbart. São Paulo: Editora 34, 2006.

DELEUZE, G.; GUATTARI, F. Mil Platôs: capitalismo e esquizofrenia. v. 2. Trad. de Peter Pál Pelbart e Janice Caiafa. São Paulo: 34, 2005.

DELEUZE, G.; GUATTARI, F. Mil Platôs: capitalismo e esquizofrenia. v. 1. Trad. de Aurélio Guerra Neto e Célia Pinto Costa. São Paulo: 34, 1995.

DUCROT, O. O dizer e o dito. Revisão técnica da tradução de Eduardo Guimarães. Campinas: Pontes, 1987.

FOUCAULT, M. A verdade e as formas jurídicas. Trad. de Roberto C. de M. Machado e Eduardo J. Morais. Rio de Janeiro: Nau Ed. 2002.

GUATTARI, F. Caosmose: um novo paradigma estético. Trad. de Ana Lúcia Oliveira e Lúcia C. Leão. São Paulo: 34, 2006.

GUATTARI, F.; ROLNIK, S. Micropolitica: cartografias do desejo. Petrópolis: Vozes, 2005.

KASTRUP, V.; TEDESCO, S.; PASSOS, E. Políticas da cognição. Porto Alegre: Sulina, 2008.

MAINGUENEAU, D. Gênese dos Discursos. Trad. de Sírio Possenti. Curitiba: Criar Edições, 2005.

MAINGUENEAU, D. Cenas da enunciação. Curitiba: Criar, 2006.
MAINGUENEAU, D. Análise de textos de comunicação. Trad. de Cecília Souza-e-Silva e Décio Rocha. São Paulo: Cortez, 2002.

MAINGUENEAU, D. Novas Tendências em Análise do Discurso. Campinas: Pontes; Editora da Unicamp, 1997.

MAINGUENEAU, D. O contexto da obra literária. São Paulo: Martins Fontes, 1995.

MBEMBE, A. Crítica da Razão Negra. Trad. de Sebastião Nascimento. São Paulo: n-1 edições, 2018.

RANCIÈRE, J. O ódio à democracia. Trad. de Mariana Echalar. São Paulo: Boitempo, 2014.

ROCHA, D. Cartografias em Análise do discurso: rearticulando as noções de gênero e cenografia. DELTA, n. 29.1, 2013.

ROCHA, D.; DEUSDARÁ, B. Argumentos para uma abordagem discursiva das práticas de linguagem no trabalho. Letras de Hoje, v. 49, p. 297-305, 2014.

ROCHA, D.; DEUSDARÁ, B. “Análise de conteúdo e Análise do discurso: o linguístico e seu entorno". DELTA, São Paulo, v. 22, n. 1, 2005, p. 29-52.

ROLNIK, S. Cartografia sentimental: transformações contemporâneas do desejo. Porto Alegre: Sulina, Ed. da Ufrgs, 2007. 